\title{
Is social support associated with improved clinical outcomes in geriatric lung cancer patients? Observations from North Central Cancer Treatment Group Studies N992I and N0222
}

This article was published in the following Dove Press journal:

Cancer Management and Research

16 June 2009

Number of times this article has been viewed

\author{
Aminah Jatoi' \\ Shauna L Hillman' \\ Katie L Allen Ziegler \\ Philip J Stella ${ }^{2}$ \\ Gamini S Soori ${ }^{3}$ \\ Kendrith M Rowland Jr \\ 'Mayo Clinic and Mayo Foundation, \\ Rochester, MN, USA; ${ }^{2}$ Michigan \\ Cancer Research Consortium, Ann \\ Arbor, MI, USA; ${ }^{3}$ Missouri Valley \\ Cancer Consortium, Omaha, NE, USA; \\ ${ }^{4}$ Carle Cancer Center CCOP, Urbana, \\ IL, USA
}

Background: Social support is defined as a network of family/friends who provide practical and emotional help. A sizable literature describes a direct relationship between social support and improved cancer clinical outcomes. This study explored the extent of social support and its potential association with survival and adverse events in geriatric lung cancer patients.

Methods: One hundred thirteen patients, who were aged 65 years or older, had incurable cancer, and were enrolled in one of two chemotherapy trials, completed the Lubben Social Network Scale, a validated instrument that measures social support. All were followed for survival and chemotherapy-related adverse events.

Results: The median age (range) of the cohort was 74 years (65-91), and performance scores of 0,1 , or 2 were observed in $29 \%, 55 \%$, and $16 \%$, respectively. Forty-two percent were women. This cohort had a high level of social support: $81 \%$ reported they "always" had someone to take them to medical appointments. However, there were no gender-based differences in social support and no associations between social support and either survival or adverse events.

Conclusion: In this cohort of geriatric lung cancer patients - all of whom were treated during a clinical trial - there was a high level of social support. However, there were no gender-based differences in extent of social support, and the latter did not predict clinical outcomes.

Keywords: social support, lung cancer, elderly, adverse events, survival

Social support is defined as a network of family and friends who provide practical help and emotional encouragement. ${ }^{1}$ A sizable but controversial literature describes a direct relationship between high levels of social support and improved clinical outcomes in cancer patients. ${ }^{2-5}$ Falagas and colleagues recently completed a systematic review of the effect of psychosocial factors on clinical outcomes among breast cancer patients. ${ }^{4}$ Reporting on 31 studies, these investigators observed that over $80 \%$ of studies detected a direct, statistically significant association between longer survival and at least one psychosocial parameter, which included strong social support. Although an exact explanation for this direct relationship between social support and improved cancer outcomes has not been elucidated, it appears that factors such as reliable transportation to medical appointments and closer monitoring at home for side effects may explain this relationship. The foregoing observations underscore a need to study social support further in other cancer settings.

Social support is highly relevant to geriatric lung cancer patients. In general, geriatric patients suffer from lack of social support because of the demise of their peers
Mayo Clinic, 200 First Street, SW

Rochester, MN 55905, USA

Fax + I 507284 I803

Email jatoi.aminah@mayo.edu
(C) 2009 Jatoi et al, publisher and licensee Dove Medical Press Ltd.This is an Open Access article which permits unrestricted noncommercial use, provided the original work is properly cited. 
and consequent social isolation. ${ }^{6,7}$ Often times, the older an individual, the less social support available. ${ }^{6,7}$ Women are especially vulnerable because they often outlive men, ${ }^{8}$ and, importantly, women often provide a major component of social support within families, thus leaving little such support directly available for themselves. ${ }^{9}$ At the same time, however, lung cancer patients specifically have greater needs for social support because of diminished mobility, concomitant morbidity, and an accelerated decline in overall health status. ${ }^{10-13}$ Thus, the literature on social support raises questions relevant to geriatric lung cancer patients and women in particular.

In view of this previously reported association between social support and improved clinical outcomes, the goals of the present study were as follows: 1) To provide descriptive data on the extent of social support in geriatric lung cancer patients about to start cancer treatment and to explore whether such social support predicts clinical outcomes and 2) to explore the existence of gender differences in social support among geriatric lung cancer patients.

\section{Materials and methods Overview}

This study was conducted within the North Central Cancer Treatment Group, a national cancer cooperative group that is funded in part by the National Cancer Institute. Questionnaire and clinical trial data from two separate cancer therapeutic trials, N9921 and N0222 were utilized. These two trials recruited patients between February 2000 and February 2001 and between December 2004 and February 2006, respectively. The present study's design was formulated prior to the initiation of the first trial and entailed merging and analyzing data from both of these prospectively conducted clinical trials.

\section{Patient eligibility}

Eligibility criteria for these two trials focused on selecting patients who could tolerate the chemotherapy agents, gefitinib, paclitaxel, and carboplatin, which were used in one or both of the trials mentioned above. These criteria are described in greater detail elsewhere, ${ }^{14,15}$ but relevant factors consistent between both trials included the following: 1) patient aged 65 years or older; 2) Eastern Cooperative Group performance score (an often-utilized score that describes the level of function of cancer patients) of 0,1 , or $2 ; 3$ ) histologic or cytologic confirmation of non-small cell lung cancer; 4) unresectable cancer; 5) no prior chemotherapy; 6) physician-anticipated life expectancy of 12 weeks or longer; and 7) absence of a major medical illness that would preclude participation in a therapeutic cancer clinical trial. In addition, all patients had to have had adequate organ function, as demonstrated by an acceptable hemogram, liver function tests, and serum creatinine at the time of study enrollment. Other eligibility criteria were more specific to each chemotherapy regimen patients were about to receive, such as, for example, an exclusion of patients with severe neuropathy in the event they were to receive paclitaxel. Otherwise, there were no major differences in eligibility criteria between the two studies.

\section{Patient enrolment and follow-up}

All eligible patients completed the Lubben Social Network Scale within 14 days of trial registration and prior to receiving any chemotherapy. This 12-item instrument has been previously validated, has been tested in a variety of settings, and includes questionnaire items that are highly germane to defining extent of social support. ${ }^{16}$ Thereafter patients were treated with one of the following chemotherapy regimens: 1) weekly carboplatin and paclitaxel (intravenous); 2) weekly carboplatin and paclitaxel (intravenous) potentially for four months followed by daily gefitinib (oral); or 3) daily gefitinib (oral). Patients were to continue cancer therapy until evidence of cancer progression, until unacceptable side effects occurred, or, for a maximum of four months, if they were receiving conventional chemotherapy. All patients were seen by their treating oncologist every 3-4 weeks. They were monitored indefinitely for cancer therapy-related side effects by means of the Common Terminology Criteria, version 2 from the National Cancer Institute. ${ }^{17}$ Tumor response as assessed by the RECIST criteria, ${ }^{18}$ and overall survival was assessed.

\section{Statistical analyses}

The sample sizes for the two individual trials were calculated to obtain adequate statistical power for the primary aims of these clinical trials, not for the social support aims. Nonetheless, for the current study, we conducted a retrospective power calculation for the comparisons of two independent means to evaluate the power available for comparing the Lubben Social Support score by the dichotomous factors of gender, performance score, and severe adverse events. The sample size of 113 (56 in each group) with an observed standard score deviation of 17 and an observed median social support score of 72 yields $84 \%$ power to detect a difference of 12 points (60 versus 72) using a two-sided alpha of 0.007 .

Scores from the Lubben Social Support Network (Items 1-10 on Table 2) were summed for analyses and then transformed to a $100 \%$ scale. A score of 0 represents the lowest possible level of social support; whereas, a score of 
100 represents the highest possible level of social support. To transform the scores to a $100 \%$ scale, a patient's individual score was divided by the patient's possible range accounting for any missed items (maximum minus minimum) and multiplied by 100 .

A rank sum test was used to evaluate whether social support scores differed based on the characteristics of gender, age $(>=70)$, and performance status. Similarly, a rank sum test was also used to evaluate whether social support scores differed between patients who suffered more severe adverse events (grade 3 or worse) versus those who did not. Time-to-cancer progression was defined as the time from registration to documentation of cancer progression. Survival time was defined as the time from study registration to death due to any cause. The distribution of survival time was estimated using the Kaplan-Meier method. A Cox proportional hazards model, which adjusted for cancer treatment, performance score, age, gender, and sum of target lesions at baseline, was used to evaluate whether social support scores were related to time-to-cancer progression or overall survival. In order to illustrate the influence of social support on overall survival, we divided the cohort by social support score quartiles. No widely accepted cutpoints exist to separate social support into categories, so quartiles were used to distribute evenly the 113 patients into four groups. A logistic regression model, which adjusted for the same baseline factors mentioned above, was used to assess relationships between social support and adverse events. Because of the exploratory nature of these analyses and because of the number of statistical tests performed, a p-value of $<0.01$ was considered statistically significant. This decision to utilize this p-value was based on the computation that the overall conventional alpha level is 0.05 and that seven multiple comparisons were made with a Bonferroni adjustment. All statistical analyses were conducted with SAS software (SAS Institute, Cary, NC, USA).

\section{Results \\ Demographics}

A total of 113 patients met the eligibility criteria, received chemotherapy on a clinical trial, and therefore participated in the current study. One patient did not receive chemotherapy, and two did not meet the eligibility criteria described earlier; thus, these three patients are not included in the analyses. Forty-two percent of the cohort consisted of women, and the median age (range) was 74 years $(65,91)$. At the time of study entry, a performance score of 0,1 , or 2 was observed in $29 \%, 55 \%$, and $16 \%$ of the cohort, respectively. Other demographics are shown in Table 1.

\section{Social support scores, gender, and clinical prediction}

Lubben Social Network Scale data are summarized in Table 2. Of note, $44 \%$ of patients reported that they see nine or more relatives at least once a month, and $27 \%$ reported that they see five to eight. Forty-eight percent see such relatives daily. In addition, $73 \%$ reported that when they have an important decision to make, they "always" have someone to talk with.

Table I Baseline patient characteristics*

\begin{tabular}{|c|c|c|c|}
\hline & N0222 & N992I & Overall \\
\hline $\mathbf{N}$ & 63 & 50 & 113 \\
\hline Median age (range) & $76(65-91)$ & $73(65-85)$ & $74(65-9 I)$ \\
\hline \multicolumn{4}{|l|}{ Gender } \\
\hline Female & $27(43)$ & $20(40)$ & $47(42)$ \\
\hline Male & $36(57)$ & $30(60)$ & $66(58)$ \\
\hline \multicolumn{4}{|l|}{ Performance status } \\
\hline 0 & $18(29)$ & $15(30)$ & $33(29)$ \\
\hline I & $38(60)$ & $24(48)$ & $62(55)$ \\
\hline 2 & $7(\mathrm{II})$ & II (22) & $18(16)$ \\
\hline \multicolumn{4}{|l|}{ Stage } \\
\hline IB & I (2) & $0(0)$ & $\mathrm{I}(\mathrm{I})$ \\
\hline IIIA & $2(3)$ & $0(0)$ & $2(2)$ \\
\hline IIIB & $12(19)$ & $0(0)$ & $12(11)$ \\
\hline IV & $48(76)$ & $0(0)$ & $48(42)$ \\
\hline Locally advanced & $0(0)$ & $7(14)$ & $7(6)$ \\
\hline Metastatic & $0(0)$ & $44(86)$ & $43(38)$ \\
\hline
\end{tabular}

Note: *Parentheses denote the percentage of patients (\%) unless otherwise specified. 
Table 2 Lubben social network scale*

I. How many relatives do you see or hear from at least once a month? (Note: Include in-laws with relatives.)

Zero

One

Two

Three or Four

Five to Eight

Nine or More

2. Tell me about the relative with whom you have the most contact. How often do you see or hear from that person?

Missing, did not answer

$<$ Monthly

Monthly

A few times a month

Weekly

A few times a week

Daily

3. How many relatives do you feel close to? That is, how many of them do you feel at ease with, can talk to about private matters, or can call on for help?

Missing

Zero

One

Two

Three or four

Five to eight

Nine or more

4. Do you have any close friends? That is, how many of them do you feel at ease with, can talk to about private matters, or can call on for help?

Missing

Zero

One

Two

Three or four

Five to eight

Nine or more

5. How many of these friends do you see or hear from at least one a month?

Missing

Zero

One

Two

Three or four

Five to eight

Nine or more

6. Tell me about the friend with whom you have the most contact. How often do you see or hear from that person? Missing

$<$ Monthly

Monthly

A few times a month

Weekly

A few times a week

Daily
$\mathbf{N}$

2

5

5

20

31

50

$\begin{array}{ll}1 & 1 \\ 2 & 2 \\ 1 & 1 \\ 6 & 5 \\ 21 & 19 \\ 28 & 25 \\ 54 & 48\end{array}$

48

$\begin{array}{ll}1 & 1 \\ 0 & 0 \\ 6 & 5 \\ 15 & 13 \\ 37 & 33 \\ 20 & 18 \\ 34 & 30\end{array}$

$\begin{array}{ll}1 & 1 \\ 9 & 8 \\ 13 & 12 \\ 14 & 12 \\ 40 & 35 \\ 17 & 15 \\ 19 & 17\end{array}$

I 1

109

II 10

$15 \quad 13$

$40 \quad 35$

$20 \quad 18$

$16 \quad 14$

65

II 10

44

98

$28 \quad 25$

$29 \quad 26$

$26 \quad 23$

(Continued) 
Table 2 (Continued)

\begin{tabular}{|c|c|c|}
\hline & $\mathbf{N}$ & $\%$ \\
\hline \multicolumn{3}{|c|}{ 7. When you have an important decision to make, do you have someone you can talk to about it? } \\
\hline Missing & 3 & 3 \\
\hline Always & 82 & 73 \\
\hline Very often & 9 & 8 \\
\hline Often & 8 & 7 \\
\hline Sometimes & 9 & 8 \\
\hline Seldom & 2 & 2 \\
\hline Never & 0 & 0 \\
\hline \multicolumn{3}{|c|}{ 8. When other people you know have an important decision to make, do they talk to you about it? } \\
\hline Missing & 3 & 3 \\
\hline Always & 23 & 20 \\
\hline Very often & 16 & 14 \\
\hline Often & 24 & 21 \\
\hline Sometimes & 33 & 29 \\
\hline Seldom & 10 & 9 \\
\hline Never & 4 & 4 \\
\hline \multicolumn{3}{|c|}{$\begin{array}{l}\text { 9a. Dose anybody rely on you to do something for them each day? For example: shopping, cooking, dinner, doing repairs, } \\
\text { cleaning, etc.? }\end{array}$} \\
\hline Missing & 8 & 7 \\
\hline No & 64 & 57 \\
\hline Yes & 41 & 36 \\
\hline \multicolumn{3}{|c|}{$\begin{array}{l}\text { 9b. Do you help anybody with things like shopping, filling out forms, doing repairs, providing child care, etc.? (was only } \\
\text { to be answered if Question \#9a was answered "No") }\end{array}$} \\
\hline Missing, did not answer or was not supposed to answer & 54 & 48 \\
\hline Always & I & 1 \\
\hline Very often & 4 & 4 \\
\hline Often & 7 & 6 \\
\hline Sometimes & 13 & 12 \\
\hline Seldom & 16 & 14 \\
\hline Never & 18 & 16 \\
\hline \multicolumn{3}{|l|}{ 10. Do you live alone or with other people? } \\
\hline Missing & 3 & 3 \\
\hline Live with spouse & 74 & 65 \\
\hline Live with other relatives or friends & 9 & 8 \\
\hline Live with other unrelated individuals (eg, paid help) & 2 & 2 \\
\hline Live alone & 25 & 22 \\
\hline \multicolumn{3}{|c|}{ II. When you have medical appointments, do you have friends or relatives who can help you get there and back? } \\
\hline Missing & 2 & 2 \\
\hline Always & 93 & 82 \\
\hline Very often & 4 & 4 \\
\hline Often & 11 & 10 \\
\hline Sometimes & I & 1 \\
\hline Seldom & I & 1 \\
\hline Never & I & 1 \\
\hline \multicolumn{3}{|c|}{ 12. If you were able to have any side effects from the medication, do you have friends or relatives who can help? } \\
\hline Missing & 2 & 2 \\
\hline Always & 80 & 71 \\
\hline Very often & 9 & 8 \\
\hline Often & 17 & 15 \\
\hline Sometimes & 4 & 4 \\
\hline Seldom & 1 & 1 \\
\hline Never & 0 & 0 \\
\hline
\end{tabular}

Note: *Percentages may not add up to $100 \%$ because of rounding. 
Finally, 82\% reported that they "always" have someone who can take them to their medical appointments, and $71 \%$ reported that they "always" have someone from whom they can seek help if they have medication side effects.

The median transformed social support score for the entire cohort (range) was 72 (30-100). It should be noted that, although normative reference data are not readily available, a community-based study among a group of 7,524 older individuals observed a similarly-derived, average social support score of $63 .{ }^{19}$ Among women and men in the present study, the average score was not statistically different: 72 in both (rank sum, $\mathrm{p}=0.87$ ) (Figure 1). Additionally, there was no statistically significant difference in social support scores among patients with an Eastern Cooperative Oncology Group performance score of 0 versus 1 and 2: median score 74 and 70 (rank sum, $\mathrm{p}=0.06$ ).

Similarly, there was no consistent evidence that social support scores predicted clinical outcomes. Although there was a trend to suggest that higher social support scores ironically predicted a shorter time-to-cancer-progression $(\mathrm{p}=0.02$; hazard ratio $[\mathrm{HR}]=1.02 ; 95 \%$ confidence interval [CI]: 1.00-1.03), these scores did not predict overall survival $(\mathrm{p}=0.34 ; \mathrm{HR}=1.01 ; 95 \% \mathrm{CI}: 0.99-1.02)$ (Figure 2). There was also no statistically significant difference in scores between patients who suffered grade 3 or worse adverse events and those who did not: median score 74 and 70 (rank sum, $\mathrm{p}=0.28$ ) (adjusted logistic regression $\mathrm{p}=0.70$; odds ratio $[\mathrm{OR}]=1.00 ; 95 \% \mathrm{CI}: 0.97-1.02)($ Table 3$)$.

\section{Discussion}

The present study was designed to assess and evaluate the role of social support in a group of geriatric non-small cell lung cancer patients who were enrolled in two different cancer therapeutic clinical trials. This study found that this cohort of geriatric patients had high levels of social support, as suggested by the fact that $81 \%$ reported that they "always" had someone who could take them to medical appointments, and $71 \%$ reported that they "always" had someone from whom they could seek help if they had medication side effects. However, social support was not associated with improved survival or diminished side effects from chemotherapy. Moreover, no differences were observed between men and women in terms of baseline social support. Thus, although previous studies have reported that social support carries a



Figure I Box plots show no gender differences for social support. 


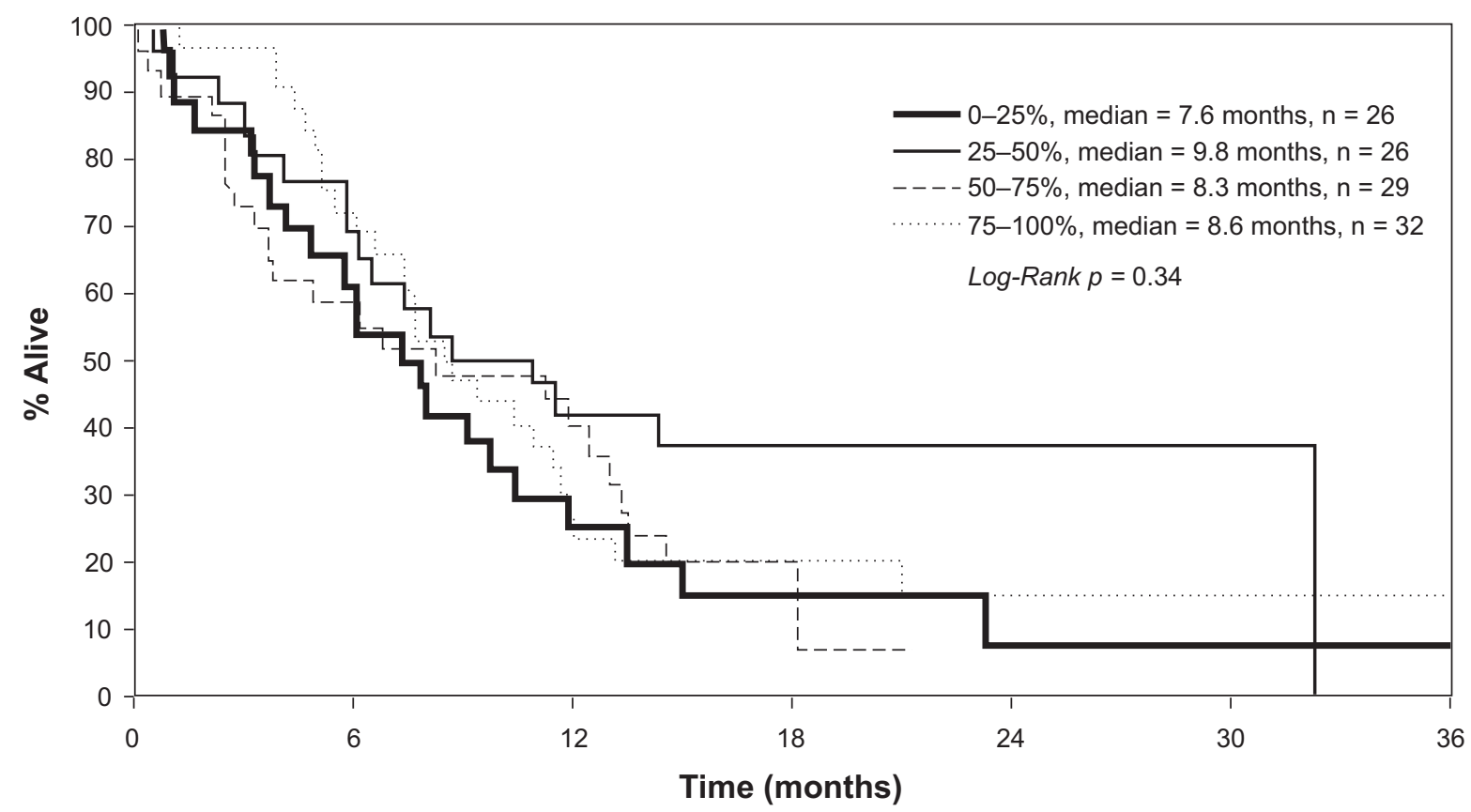

Figure 2 Kaplan-Meier survival curves are shown based on extent of social support as shown in quartiles.*

Notes: *25th percentile, social support score range (0-57); 50th percentile, social support score range (58-7I); 75 th percentile, social support score range (72-79); and I00th percentile, social support score range (80-100).

positive impact on clinical outcomes and although gender differences in extent of social support have been hypothesized, the present study did not observe such findings.

Why might the results of this study be divergent from the others that preceded it? First, relying on a clinical trial to answer such questions provides a solid infrastructure that ensures reliable outcome data. The fact that all clinical trial participants were followed prospectively in such a thorough and systematic fashion makes it unlikely that patients - particularly those who have poor social support and who are thereby especially vulnerable to being lost to follow up - would, in fact, be lost to follow up. Such artificially compromised outcomes were side-stepped by building the study around two clinical trials, as was done here. Thus, the present study's meticulous follow up may have allowed for a more definitive and accurate assessment of the predictive capabilities - or lack thereof - of social support.

Second, and more importantly, one might argue that patients' willingness to participate in a clinical trial is associated with a high level of social support and that this selection bias may have contributed to the lack of differences between groups. The fact that $82 \%$ of patients reported that they "always" had someone to bring them to medical appointments speaks to the possibility that this group as a whole has a high level of social support. Similarly, the median social support score of 72 in this study appears greater than the 63 score

Table 3 Social support scores and adverse events

\begin{tabular}{ll}
\hline & $\begin{array}{l}\text { Social support score } \\
\text { (median) }\end{array}$ \\
\hline Grade 3+ adverse events: & 74 \\
Yes $(n=66)$ & 70 \\
No $(n=47)$ & \\
Grade 3+ nonhematologic adverse events & 74 \\
Yes $(n=63)$ & 70 \\
No $(n=50)$ & \\
Grade $3+$ hematologic adverse events & 0.14 \\
Yes $(n=9)$ & 64 \\
No $(n=104)$ & 72 \\
\hline
\end{tabular}

Note: *Per the rank sum test. 
derived from a community-based study, an observation that also suggests cancer clinical trial participants have high levels of social support. ${ }^{19}$ In short, although the findings from this study suggest that social support does not influence clinical outcomes, these findings might pertain to only a culled group of geriatric clinical trial participants. Future studies may choose to focus further on the extent of social support among geriatric patients who participate in clinical trials, and further studies may also choose to study further whether social support is a predictive factor for the patients who can and do enroll in cancer clinical trials.

Two final points merit further discussion. First, although the current study did not find that social support was predictive of outcomes, there are a variety of other potentially clinically relevant factors that had not been captured and adjusted for. These include socioeconomic status, ongoing tobacco use, use of nutritional supplements, as well as several other factors. Other investigators may choose to further study the issue of social support in the context of these other factors. Second, although this study found that social support is not associated with clinical outcomes among elderly lung cancer patients, there remains no question that these patients have major needs that are likely exacerbated by a lack of social support. Patients with metastatic non-small cell lung cancer suffer from a poor prognosis, as seen from both studies presented here where the prognosis was poor, and previous studies have demonstrated that elderly patients suffer from a wide constellation of cancerrelated symptoms, including depression, guilt, debility, pain, and dyspnea. ${ }^{10-13}$ Although the present study did not observe an association between social support and clinical outcomes, there nonetheless remains a strong need for maximizing social support to help with some of the cancer-related challenges these patients face.

\section{Disclosure}

This study was conducted as a collaborative trial of the North Central Cancer Treatment Group and Mayo Clinic and was supported in part by Public Health Service grants CA-25224, CA-37404, CA-63848, CA-63849, and CA-35195. The authors report no conflicts of interest in this work.

\section{References}

1. Jackson JM, Rolnick SJ, Coughlin SS, et al. Social support among women who died of ovarian cancer. Support Care Cancer. 2007;15:547-556.

2. Weihs KL, Simmens SJ, Mizrahi J, et al. Dependable social relationships predict overall survival in stages II and III breast carcinoma patients. J Psychosom Res. 2005;59:299-306.

3. Ringdal GI, Ringdal K, Jordhoy MS, Kaasa S. Does social support from family and friends work as a buffer against reactions to stressful life events such as terminal cancer? Palliat Support Care. 2007;5:61-69.

4. Falagas M, Zarkadoulia EA, Ioannidou EN, et al. The effect of psychosocial factors on breast cancer outcome: a systematic review. Breast Cancer Res. 2007;9:R44.

5. Chida Y, Hamer M, Wardle J, Steptoe A. Do stress-related psychosocial factors contribute to cancer incidence and survival? Nat Clin Prac Oncol. 2008;5:466-475.

6. Owen T. Working with socially isolated older people. Br J Community Nurs. 2007;12:115-116.

7. Kharicha K, Iliffe S, Harari D, et al. Health risk appraisal in older people: are older people living alone an "at-risk" group? $\mathrm{Br} J \mathrm{Gen}$ Pract. 2007;57:267-268.

8. Austad SN. Why women live longer than men: sex differences in longevity. Gender Med. 2006;3:79-92.

9. Emslie C, Browne S, Macleod U, Rozmvits L, Mitchell E, Ziebland S. 'Getting through' not 'going under': A qualitative study of gender and spousal support after diagnosis with colorectal cancer. Soc Sci Med. 2009;68(6):1169-1175.

10. Mohan A, Singh P, Singh S, et al. Quality of life in lung cancer patients: impact of baseline clinical profile and respiratory status. Eur J Cancer Care. 2007;16:268-276.

11. Schiller JH, Harrington D, Belani CP, et al. Comparison of four chemotherapy regimens for advanced non-small cell lung cancer. N Engl J Med. 2002;346:92-98.

12. Sarna L, Padilla G, Holmes C, et al. Quality of life of long-term survivors of non-small cell lung cancer. J Clin Oncol. 2002;20:2920-2929.

13. Hopwood P, Stephens RJ. Depression in patients with lung cancer: prevalence and risk factors derived from quality-of-life data. J Clin Oncol. 2000;18:893-903.

14. Jatoi A, Hillman S, Stella P, et al. Why do oncologists prescribe - or not prescribe - conventional chemotherapy to geriatric patients with metastatic non-small cell lung cancer? J Support Oncol. 2006;4:311-312.

15. Jatoi A, Stella PJ, Hillman S, et al. Weekly carboplatin and paclitaxel in elderly non-small cell lung cancer patients: a phase II North Central Cancer Treatment Group study. Am J Clin Oncol. 2003;26:441-447.

16. Lubben JE, Weiler PG, Chi I. Health practices of the elderly poor. Am J Public Health. 1989;79:731-734.

17. National Cancer Institute. Protocol development. CTC v2.0 and common terminology criteria for adverse events v3.0 (CTCAE). May 29, 2008. Accessed on March 1, 2009. Available from: http://ctep. cancer.gov/protocolDevelopment/electronic_applications/ctc.htm.

18. Therasse P, Arbuck SG, Eishenhauer EA, et al. New guidelines to evaluate the reponse to treatment in solid tumors. $J$ Natl Cancer Inst. 2000;92:205-216.

19. Rutledge T, Matthews K, Lui LY, et al. Social networks and marital status predict mortality in older women: prospective evidence form the study of osteoporotic fractures. Psychosom Med. 2003;65:688-694.
Cancer Management and Research

\section{Publish your work in this journal}

Cancer Management and Research is an international, peer-reviewed open access journal focusing on cancer research and the optimal use of preventative and integrated treatment interventions to achieve improved outcomes, enhanced survival and quality of life for the cancer patient. The journal welcomes original research, clinical \& epidemiological

\section{Dovepress}

studies, reviews \& evaluations, guidelines, expert opinion \& commentary, case reports \& extended reports. The manuscript management system is completely online and includes a very quick and fair peerreview system, which is all easy to use. Visit http://www.dovepress.com/ testimonials.php to read real quotes from published authors. 